\title{
Association of $\mathrm{CCK}_{1}$ Receptor Gene Polymorphisms and Irritable Bowel Syndrome in Korean
}

Seon-Young Park, M.D., Jong-Sun Rew, M.D.*, Soo-Mi Lee, M.D., Ho-Seok Ki, M.D., Kyong-Rok Lee, M.D., Jun-Ho Cheo, M.D., Hyung-II Kim, M.D., Du-Yeong Noh, M.D., Young-Eun Joo, M.D., Hyun-Soo Kim, M.D., and Sung-Kyu Choi, M.D.

Division of Gastroenterology, Department of Internal Medicine, Chonnam National University Medical School, Gwangju, Korea

\section{Introduction}

Cholecystokinin (CCK) belongs to a group of endogenous molecules known as brain-gut neuropeptides and functions as a neuropeptide as well as a gut hormone. It remains unclear whether genetic variation of the CCK receptor plays a role in irritable bowel syndrome (IBS). The aim of this study was to determine and compare the allele and genotype frequencies of the $\mathrm{CCK}_{1}$ receptor polymorphisms between healthy controls and patients with IBS.

\section{Methods}

Genotyping of 80 patients with IBS (who met the Rome III criteria) and 76 healthy controls was performed. We performed PCR amplification for the CCK 1 receptor intron $1779 \mathrm{~T}>\mathrm{C}$ and Exon $1 \mathrm{G}>\mathrm{A}$. We confirmed polymorphisms by direct sequencing method.

\section{Results}

There was a significantly different trend for genotypic distributions of the $\mathrm{CCK}_{1}$ receptor polymorphism between patients with IBS and healthy controls ( $p$ for trend $=0.048$ ). The $\mathrm{CCK}_{1}$ receptor intron $1779 \mathrm{~T}>\mathrm{C}$ polymorphic type was more common in patients with 'IBS-constipation predominant (IBS-C) and IBS-mixed (IBS-M) forms' (19/31,61.3\%) than healthy controls $32 / 76,42.1 \%$ adjusted odd ratio $2.43,95 \%$ Confidence interval 1.01-5.86). The genotypic distributions of the CCK ${ }_{1}$ receptor exon 1 polymorphism were not significantly different between the two groups $(p$ for trend $=0.223$ ).

\section{Conclusions}

CCK 1 receptor polymorphisms were associated with IBS. In particular, the CCK 1 receptor intron 1779 T >C polymorphic type was associated with 'IBS-C and IBS-M'. Further studies are needed in larger number of patients with an even distribution of IBS subtypes.

(J Neurogastroenterol Motil 2010;16:71-76)

Key Words

Irritable bowel syndromes, Receptor, Cholecystokinin, Polymorphism, Genetic

Received: November 3rd, 2009 Accepted: December 12th, 2009

(c) This is an Open Access article distributed under the terms of the Creative Commons Attribution Non-Commercial License (http://creativecommons. org/licenses/by-nc/3.0) which permits unrestricted non-commercial use, distribution, and reproduction in any medium, provided the original work is properly cited.

*Correspondence: Jong-Sun Rew, M.D.

Department of Internal Medicine, Chonnam National University Medical School, 8 Hak-dong, Dong-gu, Gwangju 501-757, Korea

Financial support: None. Tel: +82-62-220-6215, Fax: +82-62-228-1330, E-mail: jsrew@chonnam.ac.kr

Conflicts of interest: None. 


\section{Introduction}

Irritable bowel syndrome (IBS) is characterized by the presence of abdominal discomfort or pain associated with disturbed defecation. IBS is important because of its high prevalence, substantial morbidity, and enormous cost. In clinical practice of gastroenterology, more than one third of the patients have functional gastrointestinal disorders, and IBS is the most common diagnosis. ${ }^{1}$ However, the etiology and physiology of IBS are not fully understood. A number of different mechanisms have been implicated in the pathogenesis of IBS including abnormal motility, visceral hypersensitivity, low-grade inflammation, and stress. ${ }^{2}$ No single pathophysiological mechanism explains the clinical manifestation of IBS entirely. Current evidence suggests that an altered brain-gut axis is the key mechanism associated with disordered motility, visceral hypersensitivity, and autonomic dysfunction. Regulation of these connections occurs via numerous neurotransmitters such as cholecystokinin (CCK), vasoactive intestinal peptide (VIP), substance $\mathrm{P}$, serotonin, and corticotrophin releasing hormone $(\mathrm{CRH}) .{ }^{3}$ Cholecystokinin $(\mathrm{CCK})$ is a neuropeptide released by endocrine I cells within the duodenal and jejunal mucosa in response to a variety of nutrients, notably the digestion products of fat, and its secretion is associated with contraction of the gallbladder, pancreas enzyme secretion, and inhibition of gastric emptying. ${ }^{4}$ Two receptor subtypes of CCK have been identified, $\mathrm{CCK}_{1}$ and $\mathrm{CCK}_{2}$, which were initially classified pharmacologically on the basis of their affinity for the endogenous peptides $\mathrm{CCK}$ and gastrin and several selective non-peptide antagonists. ${ }^{5}$ Both $\mathrm{CCK}_{1}$ and $\mathrm{CCK}_{2}$ belong to a single family of $\mathrm{G}$-coupled receptors (GPCRs): the $\mathrm{CCK}_{1}$ is predominantly located in the gastrointestinal (GI) track (previously called $\mathrm{CCK}_{\mathrm{A}}$, where $\mathrm{A}=$ alimentary), whereas the $\mathrm{CCK}_{2}$ receptor is distributed widely throughout the central nervous system (CNS) (previously called $\mathrm{CCK}_{\mathrm{B}}$, where $\mathrm{B}=$ brain). ${ }^{6}$ Blocking of the $\mathrm{CCK}_{1}$ receptors in the GI tract has been proposed as a novel approach to stimulate gut motility and to change colonic transit time in patients with constipation-predominant functional bowel disorders. ${ }^{7} \mathrm{CCK}_{1}$ receptor polymorphism in IBS patients with constipation has been associated with slower gastric emptying. ${ }^{7}$ However, it remains unclear whether genetic variation of the CCK receptor plays a role in the pathogenesis of IBS. Thus, the aim of this study was to determine and compare the allele and genotype frequencies for the $\mathrm{CCK}_{1}$ receptor polymorphism between healthy controls and patients with IBS.

\section{Materials and Methods}

\section{Subjects}

This was a case-control study. The subjects in this study were recruited between March 2007 and February 2008. Eighty outpatients with IBS, who were referred to a tertiary hospital and 76 healthy controls, who visited the health promotion center for a routine checkup were enrolled. The subjects with IBS were diagnosed according to the Rome III criteria. ${ }^{8}$ Healthy controls had no prior history of disease or symptoms related to the gastrointestinal system in the study. IBS subjects were excluded if they had an unstable medical disorder, another gastrointestinal disorder, a major psychiatric disorder, or a history of substance abuse within the previous two years.

This study was approved by the institutional review board of the Chonnam National University Hospital, Gwangju, Korea. All subjects were provided with written information on the project, and informed consent was obtained as well.

\section{Genotyping}

Venous blood drawn from a forearm vein was stored at $-70^{\circ} \mathrm{C}$. DNA was extracted from whole blood by the alkaline lysis method using the QIAamp DNA Midi Kit (Qiagen Inc., Valencia, CA, USA). We examined the DNA for the $\mathrm{CCK}_{1}$ receptor polymorphisms in intron 1 and exon 1 . We performed PCR amplification using GeneAmp 2700 for the $\mathrm{CCK}_{1}$ receptor intron $1779 \mathrm{~T}>\mathrm{C}$ and Exon $1 \mathrm{G}>\mathrm{A}$. The forward primers and reverse primers used for the $\mathrm{CCK}_{1}$ receptor intron $1779 \mathrm{~T}$ $>$ C were 5'-CTG TTC ACT TGA GGA GCT TTG-3' and 5'-TTA GAA ACT GAC CTC CAA CAT GG-3'. The forward primers and reverse primers used for Exon $1 \mathrm{G}>\mathrm{A}$ were 5'-ATG AGC CGG GAG TGA GCA AT-3' and 5'-GCC TTT GCT GAT TTC TCC CAC-3' (GeneBank accession number \#U23427). Amplification of intron $1779 \mathrm{~T}>\mathrm{C}$ and Exon $1 \mathrm{G}>\mathrm{A}$ was performed in a 25 reaction volume containing $100 \mathrm{ng}$ of genomic DNA, Tris- $\mathrm{HCl}(\mathrm{pH} 9.0),\left(\mathrm{NH}_{4}\right)_{2} \mathrm{SO}_{4}$, $20 \mathrm{mM} \mathrm{MgCl}$, PCR enhancers in reaction buffer $2.5 \mu \mathrm{L}$, DW $16.5 \mu \mathrm{L}$, and Exprime Taq polymerase (Genet BIO Teageon, Korea) $0.5 \mu \mathrm{L}$. DNA was predenatured at $94^{\circ} \mathrm{C}$ for $10 \mathrm{~min}$, and subjected to 35 cycles of $30 \mathrm{sec}$ of denaturation at $94^{\circ} \mathrm{C}, 1 \mathrm{~min}$ of annealing at $60^{\circ} \mathrm{C}, 30 \mathrm{sec}$ of extension at $72^{\circ} \mathrm{C}$, and $10 \mathrm{~min}$ of final extension at $72^{\circ} \mathrm{C}$ (Table 1$)$. The amplification products were resolved by electrophoresis on $1.8 \%$ SeaKem LE agarose 
Table 1. Nucleotide Sequences for Assay Primer and PCR Condition for Polymorphisms in the CCK1 Receptor Polymorphisms

\begin{tabular}{|c|c|c|}
\hline & Intron 1779 & Exon 1 \\
\hline \multicolumn{3}{|l|}{ Primer } \\
\hline Forward primer sequence 5'-3' & CTGTTCACTTGAGGAGCTTTG & ATGAGCGGGAGTGAGCAAT \\
\hline Reverse primer sequence 5'-3' & TTAGAAGCTGACCTCCAACATGG & GCCTTTGCTGATTTCTCCCAC \\
\hline \multicolumn{3}{|l|}{ PCR condition } \\
\hline Predenaturing & At $94^{\circ} \mathrm{C}$ for $10 \mathrm{~min}$ & At $94^{\circ} \mathrm{C}$ for $10 \mathrm{~min}$ \\
\hline Denaturing & At $94^{\circ} \mathrm{C}$ for $30 \mathrm{sec}$ & At $94^{\circ} \mathrm{C}$ for $30 \mathrm{sec}$ \\
\hline Annealing & At $60^{\circ} \mathrm{C}$ for $60 \mathrm{sec}$ & At $60^{\circ} \mathrm{C}$ for $60 \mathrm{sec}$ \\
\hline Extension & At $72^{\circ} \mathrm{C}$ for $30 \mathrm{sec}$ & At $72^{\circ} \mathrm{C}$ for $30 \mathrm{sec}$ \\
\hline Final extension & At $72^{\circ} \mathrm{C}$ for $10 \mathrm{~min}$ & At $72^{\circ} \mathrm{C}$ for $10 \mathrm{~min}$ \\
\hline Product size & $240 \mathrm{bp}$ & $744 \mathrm{bp}$ \\
\hline
\end{tabular}

Table 2. Clinical Characteristics of the IBS Patients and Healthy Controls

\begin{tabular}{lcccc}
\hline & Healthy controls $(\mathrm{n}=76)$ & IBS patients $(\mathrm{n}=80)$ & IBS-D patients $(\mathrm{n}=49)$ & IBS-C and IBS-M patients $(\mathrm{n}=31)$ \\
\hline Female, $\mathrm{n}(\%)$ & $44(57.9)$ & $50(62.5)$ & $28(57.1)$ & $22(71.0)$ \\
Age $(\mathrm{yr})$, mean $\pm \mathrm{SD}$ & $40.2 \pm 12.8$ & $37.9 \pm 11.9$ & $38.3 \pm 12.8$ & $37.4 \pm 10.6$ \\
\hline
\end{tabular}

IBS, irritable bowel syndrome; IBS-D, IBS with diarrhea-predominant pattern; IBS-C, IBS with constipation-predominant bowel pattern; IBS-M, IBS with mixed pattern.

(Cambrex Bio Science Rockland, Inc., Rockland, ME, USA) next to a DNA molecular weight standard marker 100 bp ladder (TAKARA BIO Inc., Otsu, Shiga, Japan) and visualized with ethidium bromide staining. We confirmed polymorphisms by direct sequencing with $\mathrm{ABI}$ version 3.1 Sequence Analysis software.

\section{Statistical methods}

Statistical analysis was performed using the SPSS for Windows version 17.0 (SPSS Inc., Chicago, IL, USA). The statistical significance of the differences between the subjects with IBS and healthy controls was estimated by logistic regression analysis. Adjusted odds ratios (aORs) were calculated with a logistic regression model that were controlled by gender and age with $95 \%$ confidence intervals $(\mathrm{CI})$. A p $<0.05$ was considered as the level of significance. Mann-Whitney $U$ test were used to determine whether there were difference in the demographic data of the IBS patients and healthy controls. Subjects with wild type genotypes (intron 779 TT, exon 1 GG) were considered to be at baseline risk. The expected frequency of healthy control's genotypes was assessed by Hardy-Weinberg equilibrium test. ${ }^{9}$ Linkage disequilibrium was calculated using the SNP Analyzer program (Istech Ltd., Goyang-si, Korea).

\section{Results}

\section{Clinical characteristics of the study population}

In the IBS patients, the median age was 35 years (range 22-67 years) and female patients comprised $62.5 \%$. In healthy controls, the median age was 38 years (range 22-69 years) and female subjects comprised $57.9 \%$. There were no statistical difference between the IBS patients and healthy controls in the age or sex $(p>0.05)($ Table 2). Forty-nine of the IBS subjects had a diarrhea-predominant bowel pattern (IBS-D), 15 had a constipation-predominant bowel pattern (IBS-C), and 16 had a mixed pattern (IBS-M).

\section{CCK1 receptor intron $1779 \mathrm{~T}>\mathrm{C}$ and exon $1 \mathrm{G}>\mathrm{A}$ polymorphism in the IBS patients and in healthy controls}

The distribution of the $\mathrm{CCK}_{1}$ receptor intron 779 and exon 1 polymorphisms in healthy controls was in Hardy-Weinberg equilibrium (Intron 779; $\mathrm{p}=0.505$, exon $1 ; \mathrm{p}=0.496$ ).

1) $\mathrm{CCK}_{1}$ receptor intron $1779 \mathrm{~T}>\mathrm{C}$ polymorphism in the IBS patients and in healthy controls

Table 3 shows the genotype distributions and allele frequencies of the $\mathrm{CCK}_{1}$ receptor intron $1779 \mathrm{~T}>\mathrm{C}$ polymorphism in the IBS patients and healthy controls. There was a significantly 
Table 3. Genotype Frequency for $\mathrm{CCK}_{1}$ Receptor Intron $1779 \mathrm{~T}>\mathrm{C}$ in the IBS Patients and in Healthy Controls

\begin{tabular}{lcccc}
\hline \multicolumn{1}{c}{ Genotype } & TT & TC & CC & C carrier \\
\hline Total, n (\%) & $80(51.3)$ & $65(41.7)$ & $11(7.0)$ & $76(48.7)$ \\
Healthy controls, n (\%) & $44(57.9)$ & $29(38.2)$ & $3(3.9)$ & $32(42.1)$ \\
IBS, n (\%) & $36(45.0)$ & $36(45.0)$ & $8(10.0)$ & $44(55.0)$ \\
aOR (95\% CI) & 1 (Reference) & $1.58(0.81-3.09)$ & $3.46(0.84-14.25)$ & $1.75(0.92-3.34)$ \\
p-value & & 0.177 & 0.086 & 0.870 \\
IBS-D, n (\%) & $24(49.0)$ & $20(40.8)$ & $5(10.2)$ & $25(51.0)$ \\
aOR (95\% CI) & 1 (Reference) & $1.31(0.61-2.80)$ & $3.37(0.71-15.85)$ & $1.48(0.71-3.07)$ \\
p-value & & 0.484 & 0.134 & 0.320 \\
IBS-C and IBS-M, n (\%) & 12 (38.7) & $16(51.6)$ & $3(9.7)$ & $19(61.3)$ \\
aOR (95\% CI) & 1 (Reference) & $2.29(0.92-5.70)$ & $3.58(0.61-20.97)$ & $2.43(1.01-5.86)$ \\
p-value & & 0.082 & 0.176 & 0.048 \\
\hline
\end{tabular}

${ }^{\mathrm{a}} \mathrm{p}$ for trend $=0.048,{ }^{\mathrm{b}} \mathrm{p}$ for trend $=0.151,{ }^{\mathrm{c}} \mathrm{p}$ for trend $=0.045$.

CCK, cholecystokinin; IBS, irritable bowel syndrome; IBS, irritable bowel syndrome; IBS-D, IBS with diarrhea-predominant pattern; IBS-C, IBS with constipation-predominant bowel pattern; IBS-M, IBS with mixed pattern; OR, odds ratio; CI, confidence interval.

$\mathrm{OR}$ and $95 \% \mathrm{CI}$ were estimated using multiple logistic regression and adjusted for sex and age.

Table 4. Genotype Frequency for $\mathrm{CCK}_{1}$ Receptor Exon $1 \mathrm{G}>\mathrm{A}$ in the IBS Patients and in Healthy Controls

\begin{tabular}{lcccc}
\hline \multicolumn{1}{c}{ Genotype } & GG & GA & AA & A carrier \\
\hline Total, n (\%) & $129(82.2)$ & $27(17.2)$ & $1(0.6)$ & $28(17.8)$ \\
Healthy controls, n (\%) & $65(85.5)$ & $11(14.5)$ & $0(0.0)$ & $11(14.5)$ \\
IBS, n (\%) & $63(78.8)$ & $16(20.0)$ & $1(1.2)$ & 17 \\
aOR (95\% CI) & 1 (Reference) & $1.50(0.64-3.50)$ & - & $1.59(0.69-3.69)$ \\
p-value & & 0.348 & 0.999 & 0.28 \\
IBS-D, n (\%) & $38(77.6)$ & $11(22.4)$ & $0(0.0)$ & $11(22.4)$ \\
aOR (95\% CI) & 1 (Reference) & $1.76(0.69-4.44)$ & - & $1.75(0.29-4.44)$ \\
p-value & & 0.237 & $1(3.2)$ & 0.237 \\
IBS-C and IBS-M, n (\%) & 25 (80.6) & $5(16.1)$ & - & $6(19.3)$ \\
aOR (95\% CI) & 1 (Reference) & $1.28(0.39-4.15)$ & 0.999 & $1.55(0.51-4.76)$ \\
p-value & & 0.684 & & 0.444 \\
\hline
\end{tabular}

${ }^{\mathrm{a}} \mathrm{p}$ for trend $=0.223,{ }^{\mathrm{b}} \mathrm{p}$ for trend $=0.237,{ }^{\mathrm{c}} \mathrm{p}$ for trend $=0.269$.

CCK, cholecystokinin; IBS, irritable bowel syndrome; IBS-D, IBS with diarrhea-predominant pattern; IBS-C, IBS with constipation-predominant bowel pattern; IBS-M, IBS with mixed pattern; OR, odds ratio; CI, confidence interval.

OR and $95 \%$ CI were estimated using multiple logistic regression and adjusted for sex and age.

different trend for genotypic distributions of $\mathrm{CCK}_{1}$ receptor intron $1779 \mathrm{~T}>\mathrm{C}$ polymorphism between the IBS patients and healthy controls ( $\mathrm{p}$ for trend $=0.048$ ). However, no significant difference was observed in $\mathrm{C}$ carrier between the two groups ( $\mathrm{p}$ $=0.870)$. The TC genotype was $45 \%(36 / 80)$ in IBS patients and $38.2 \%(29 / 76)$ in controls $(\mathrm{p}=0.177, \mathrm{aOR} 1.58,95 \% \mathrm{CI}$ 0.81-3.09). The CC genotype was $10.0 \%$ (8/80) in IBS patients and $3.9 \%(3 / 76)$ in healthy control $(\mathrm{p}=0.086$, aOR $3.46,95 \%$ CI 0.84-14.25).

The $\mathrm{CCK}_{1}$ receptor intron $1779 \mathrm{~T}>\mathrm{C}$ polymorphic type (TC genotype and CC genotype) was more common in patients with 'Non IBS-D (IBS-C and IBS-M)' (19/31, 61.3\%) than it was in healthy controls $(32 / 76,42.1 \%$, aOR $2.4395 \% \mathrm{CI}$ 1.01-5.86) (Table 3).

\section{2) CCK1 receptor exon $1 \mathrm{G}>\mathrm{A}$ polymorphism in the IBS patients and in healthy controls}

The genotypic distributions ( $\mathrm{p}$ for trend $=0.223$ ) and A carrier frequencies $(\mathrm{p}=0.28)$ of the $\mathrm{CCK}_{1}$ receptor exon 1 polymorphism were not significantly different between the two groups (Table 4).

\section{Discussion}

CCK belongs to the group of endogenous molecules known 
as 'brain-gut neuropeptides' and, due to its anatomical location, it functions as a neuropeptide as well as a gut hormone. CCK is also found in the nerves of the circular muscle layer of the colon, to some extent in the ileum, and it is abundant in the celiac plexus and vagus nerves. ${ }^{10}$ Due to these multiple anatomical locations it is not surprising that $\mathrm{CCK}$ has been implicated in different physiological functions: gallbladder contraction and pancreatic enzyme secretion, as well as motor and sensory functions at various levels of the gastrointestinal tract such as gastric emptying and colonic motility. ${ }^{11}$ The role of CCK was first reported by Harvey et al. who have observed CCK to cause an abnormal increase in colonic motility in patients with IBS. ${ }^{12}$ Further studies have shown that the release of $\mathrm{CCK}$, induced by a fatty meal, acts as a mediator of the gastrocolonic response. ${ }^{13} \mathrm{CCK}$ infusion appears to unmask intestinal dysmotility in patients with IBS. ${ }^{14}$ Intraduodenal lipids increased visceral sensitivity in both IBS-D and IBS-C patients suggesting a role for CCK at the neuronal level. In patients with functional abdominal pain syndromes, infusion of $\mathrm{CCK}_{8}$ correlate with significantly higher pain scores compared to control subjects. ${ }^{15}$ Therefore, the promising potential use of $\mathrm{CCK}_{1}$ antagonists for the treatment of a variety of functional gastrointestinal disorders including IBS will be expected.

Recent reports in human subjects have shown an association between $\mathrm{CCK}_{1}$ receptor gene polymorphism and schizophrenia, ${ }^{16}$ alcohol dependence, ${ }^{17}$ panic disorder, ${ }^{18}$ gallstone disease, ${ }^{19}$ and postprandial dyspepsia. ${ }^{20}$ However, there have been no reports on the association between the $\mathrm{CCK}_{1}$ receptor polymorphism and IBS. The results of present study suggest that the $\mathrm{CCK}_{1}$ receptor intron $1779 \mathrm{~T}>\mathrm{C}$ polymorphism may be functionally important, since the genotypic distribution of the $\mathrm{CCK}_{1}$ receptor intron $1779 \mathrm{~T}>\mathrm{C}$ polymorphism in IBS patients had a significantly different trend compared to that in healthy controls ( $p$ for trend $=0.048$ ). Moreover, the findings of this study showed that the $\mathrm{CCK}_{1}$ receptor intron $1779 \mathrm{~T}>\mathrm{C}$ polymorphic type (TC genotype and CC genotype) was associated with an increased odds ratio for 'non-IBS-D (IBS-C and IBS-M)' (aOR $2.43,95 \% \mathrm{CI} 1.01-5.86)$. However, we did not find any association between the $\mathrm{CCK}_{1}$ receptor intron $1779 \mathrm{~T}>\mathrm{C}$ polymorphic type and patients with IBS-D, implying that the genetic variation was only associated with IBS patients of 'non IBS-D' type from our study. In a study of Caucasian patients, the $\mathrm{CCK}_{1}$ receptor intron $1779 \mathrm{~T}>\mathrm{C}$ polymorphism in patients with IBS-C, was associated with slower gastric emptying. This suggested that, compared to the $779 \mathrm{~T}$ variant, the $779 \mathrm{C}$ substitution resulted in an increased response to endogenous CCK (like CCK agonist), which was followed by delaying gastric emptying. ${ }^{7}$ From the viewpoint of sensory functions at various levels of the gastrointestinal tract, our results are consistent with the original hypothesis that suggested that the $\mathrm{CCK}_{1}$ receptor intron $1779 \mathrm{~T}>\mathrm{C}$ polymorphic type might have an increased response to endogenous $\mathrm{CCK}$ and be associated with visceral hypersensitivity. However, from the viewpoint of colon motility, present study showed an opposite trend to our expectation that the $\mathrm{CCK}_{1} 779 \mathrm{C}$ substitution would be related with accelerating colon transit time, like $\mathrm{CCK}$ agonist. Therefore, characterization of the $\mathrm{CCK}_{1}$ receptor polymorphism and its clinical significance require further study.

The limitations of the present study include the following. First, this study was limited by the small sample size and uneven distribution of IBS subtypes. Second, present study did not show clinical significance for the $\mathrm{CCK}_{1}$ receptor polymorphism in regard to visceral hypersensitivity and colon motility. Further studies are needed with larger patient samples with an even distribution of IBS subtypes. However, our findings suggest that the $\mathrm{CCK}_{1}$ intron $1779 \mathrm{~T}>\mathrm{C}$ polymorphism might have a significant association with IBS.

The presence of $\mathrm{CCK}_{1}$ receptor polymorphisms may indeed provide new opportunities for predicting how patients will respond to a particular treatment according to their genetic profile, and therefore may have an impact on current management strategies. Therefore, pharmacogenomic studies on $\mathrm{CCK}_{1}$ receptor polymorphisms and the CCK antagonist might be of significant interest and potential clinical relevance.

In summary, we have shown that $\mathrm{CCK}_{1}$ receptor polymorphisms are associated with IBS. In particular, the $\mathrm{CCK}_{1}$ receptor intron $1779 \mathrm{~T}>\mathrm{C}$ polymorphic type was associated with non-IBS-D. However, further studies are needed in larger patient samples with an even distribution of IBS subtypes. In addition, further studies for the characterization of $\mathrm{CCK}_{1}$ receptor polymorphisms and understanding of its clinical significance by associations with clinical outcomes are also needed.

\section{References}

1. Feldman M, Friedman LS, Brandt LJ. Irritable blowel syndrome. In: Nicholas J, ed. Sleisenger \& Fordtran's gastrointestinal and liver disease. Volume 2. 8th ed. Philadelphia: Elsevier, 2006:2633-2702.

2. Drossman DA, Camilleri M, Mayer EA, Whitehead WE. AGA technical review on irritable bowel syndrome. Gastroenterology 2002;123:2108-2131.

3. Hotoleanu C, Popp R, Trifa AP, Nedelcu L, Dumitrascu DL. 
Genetic determination of irritable bowel syndrome. World J Gastroenterol 2008;14:6636-6640.

4. Sandler RS. Epidemiology of irritable bowel syndrome in the United States. Gastroenterology 1990;99:409-415.

5. Noble F, Wank SA, Crawley JN, et al. International Union of Pharmacology. XXI. Structure, distribution, and functions of cholecystokinin receptors. Pharmacol Rev 1999;51:745-781.

6. Peter SA, D'Amato M, Beglinger C. CCK1 antagonists: are they ready for clinical use? Dig Dis 2006;24:70-82.

7. Cremonini F, Camilleri M, McKinzie S, et al. Effect of CCK-1 antagonist, dexloxiglumide, in female patients with irritable bowel syndrome: a pharmacodynamic and pharmacogenomic study. Am J Gastroenterol 2005;100:652-663.

8. Longstreth GF, Thompson WG, Chey WD, Houghton LA, Mearin F, Spiller RC. Functional bowel disorders. Gastroenterology 2006;130:1480-1491.

9. Lin DY, Zeng D, Millikan R. Maximum likelihood estimation of haplotype effects and haplotype-environment interactions in association studies. Genet Epidemiol 2005;29:299-312.

10. Liddle RA. Cholecystokinin. In: Walsh JH, Dockray GJ, eds. Gut Peptides. Biochemistry and physiology. New York: Raven, 1994: 175.

11. Crawley JN, Corwin RL. Biological actions of cholecystokinin. Peptides 1994;15:731-755.

12. Harvey RF, Read AE. Effect of cholecystokinin on colonic motility and symptoms in patients with the irritable-bowel syndrome. Lancet 1973;1:1-3.
13. Renny A, Snape WJ Jr, Sun EA, London R, Cohen S. Role of cholecystokinin in the gastrocolonic response to a fat meal. Gastroenterology 1983;85:17-21.

14. Kellow JE, Phillips SF, Miller LJ, Zinsmeister AR. Dysmotility of the small intestine in irritable bowel syndrome. Gut 1988;29:12361243.

15. Roberts-Thomson IC, Fettman MJ, Jonsson JR, Frewin DB. Responses to cholecystokinin octapeptide in patients with functional abdominal pain syndromes. J Gastroenterol Hepatol 1992;7:293297.

16. Minato T, Tochigi M, Kato N, Sasaki T. Association study between the cholecystokinin A receptor gene and schizophrenia in the Japanese population. Psychiatr Genet 2007;17:117-119.

17. Miyasaka K, Yoshida Y, Matsushita S, et al. Association of cholecystokinin-A receptor gene polymorphism with alcohol dependence in a Japanese population. Alcohol Alcohol 2004;39:25-28.

18. Miyasaka K, Yoshida Y, Matsushita S, et al. Association of cholecystokinin-A receptor gene polymorphisms and panic disorder in Japanese. Am J Med Genet B Neuropsychiatr Genet 2004;127B: 78-80.

19. Srivastava A, Pandey SN, Dixit M, Choudhuri G, Mittal B. Cholecystokinin receptor A gene polymorphism in gallstone disease and gallbladder cancer. J Gastroenterol Hepatol 2008;23:970-975.

20. Tahara T, Arisawa T, Shibata T, et al. 779 TC of CCK-1 intron 1 is associated with postprandial syndrome (PDS) in Japanese male subjects. Hepatogastroenterology 2009;56:1245-1248. 